\title{
Avaliação Socioambiental da Comunidade de Tamatateua, Zona Costeira Amazônica Brasileira
}

\author{
OLIVEIRA, Euzébio de ${ }^{[1]}$
}

OLIVEIRA, Euzébio de. Avaliação socioambiental da comunidade de Tamatateua, Zona Costeira Amazônica Brasileira. Revista Científica Multidisciplinar Núcleo do Conhecimento. Ano 01, Ed. 07, Vol. 05, pp. 37-57, Julho de 2016. ISSN: 2448-0959

\section{RESUMO}

O presente estudo aborda os aspectos socioeconômicos e ambientais de Tamatateua, uma comunidade agro-pesqueira, localizada na zona costeira do nordeste do Estado do Pará, Brasil. Essa comunidade está inserida na área que compreende a Reserva Extrativista Marinha Caeté - Taperaçu. Este estudo foi realizado através de entrevistas, uso de questionários, observação direta e mensuração dos principais problemas ambientais, seguindo metodologias específicas. Os resultados mostraram que essa comunidade possui uma precária situação socioeconômica e é caracterizada por uma população jovem, com baixo grau de escolaridade, que sobrevive com menos de um salário mínimo por mês. A comunidade apresenta problemas relacionados à falta de serviços e infra-estrutura, e ao uso inadequado dos recursos naturais. Falta interesse das autoridades governamentais para investir nos serviços públicos e fiscalizar/penalizar a exploração dos recursos naturais na área da RESEX. Propostas de medidas de gestão costeira participativa foram lançadas no presente trabalho, visando à melhoria da qualidade de vida e ambiental na área estudada.

Palavras chaves: Degradação socioambiental, uso e ocupação territorial, zona costeira amazônica.

\section{INTRODUÇÃO}

Nos últimos anos, os ecossistemas costeiros têm sofrido sérias mudanças, principalmente, em resposta ao grande crescimento populacional humano e às atividades econômicas desenvolvidas nessas regiões (Jiang et al., 2001; Billé \& Mermet, 2002). Processos de caráter natural e antrópico, em âmbito regional e global, como por exemplo, o aumento do nível do mar, mudanças climáticas, urbanização desordenada, desmatamento, poluição de mares, estuários e rios, entre outros vêm sendo responsáveis pelo comprometimento (quali-quantitativo) dos recursos naturais existentes nestes ecossistemas (REID; 
TREXLER, 1992; WEAVER; GREEN, 1998; SOUZA; NEUMANN LEITÃO, 2000).

O Brasil possui, aproximadamente, $7.408 \mathrm{~km}$ de linha de costa, sendo que cerca de $70 \%$ da população brasileira habita os principais centros urbanos existentes ao longo do litoral (CNIO, 1998). A costa amazônica brasileira representa, cerca de, $35 \%$ do litoral do país e está formada pelos estados do Amapá, Pará e Maranhão que juntos perfazem mais de $2.500 \mathrm{~km}$ de extensão (Isaac \& Barthem, 1995). Essa região apresenta um ambiente naturalmente rico e muito produtivo, do ponto de vista biológico, com amplas áreas de manguezais, estuários, rios e florestas tropicais, apresentando fauna e flora bastante peculiar e variada, que interligam tanto ambientes terrestres quanto aquáticos (CARVALHO; RIZZO, 1994; GLASER, 2003).

No nordeste do Estado do Pará, estudos mostram que a crescente pressão do homem, sobre os ecossistemas ali existentes, tem gerado vários problemas socioambientais, em decorrência principalmente do desmatamento, ocupação desordenada, falta de serviços e infra-estrutura, contaminação do solo e do sistema hídrico, extração predatória dos recursos pesqueiros, dentre outros (SILVA et al., 2006; PEREIRA et al., 2006A; PEREIRA et al., 2007).

Entre os municípios do NE do estado, Bragança destaca-se por possuir um dos maiores potenciais de exploração dos recursos pesqueiros da região (KRAUSE; GLASER, 2003), tendo sido considerada, na década de 90, o terceiro maior pólo de desembarque de pescado do estado (ESPÍRITO SANTO et al., 2005), bem como um dos maiores produtores agrícolas da região. Entre as várias comunidades rurais existentes no município de Bragança, a comunidade agro-pesqueira de Tamatateua se destaca por estar inserida na Reserva Extrativista Marinha Caeté-Taperaçu (MMA, 2005).

Neste contexto, o objetivo deste trabalho foi estudar os aspectos socioambientais de Tamatateua, bem como propor medidas de gestão integrada para a área rural da RESEX Caeté-Taperaçu, utilizando a comunidade de Tamatateua como estudo de caso, uma vez que a mesma apresenta uma densidade demográfica representativa e uma organização social relativamente estruturada, se comparada às demais comunidades integrantes desta RESEX marinha. Para alcançar este objetivo foi necessário conhecer o perfil socioeconômico dos moradores, determinar os tipos de uso e ocupação territorial local, bem como caracterizar os principais problemas ambientais detectados. Por fim, propostas de medidas de gestão costeira participativa foram lançadas, visando à melhoria da qualidade de vida e ambiental das comunidades rurais situadas nesta unidade de conservação.

\section{METODOLOGIA}

\section{1 ÁREA DE ESTUDO}

A comunidade do Tamatateua localiza-se ao norte do centro da cidade de Bragança, litoral nordeste do Estado do Pará, sendo uma das comunidades agro-pesqueiras inseridas na Reserva Extrativista Marinha Caeté-Taperaçu (MMA, 2005). (Figura 1). 


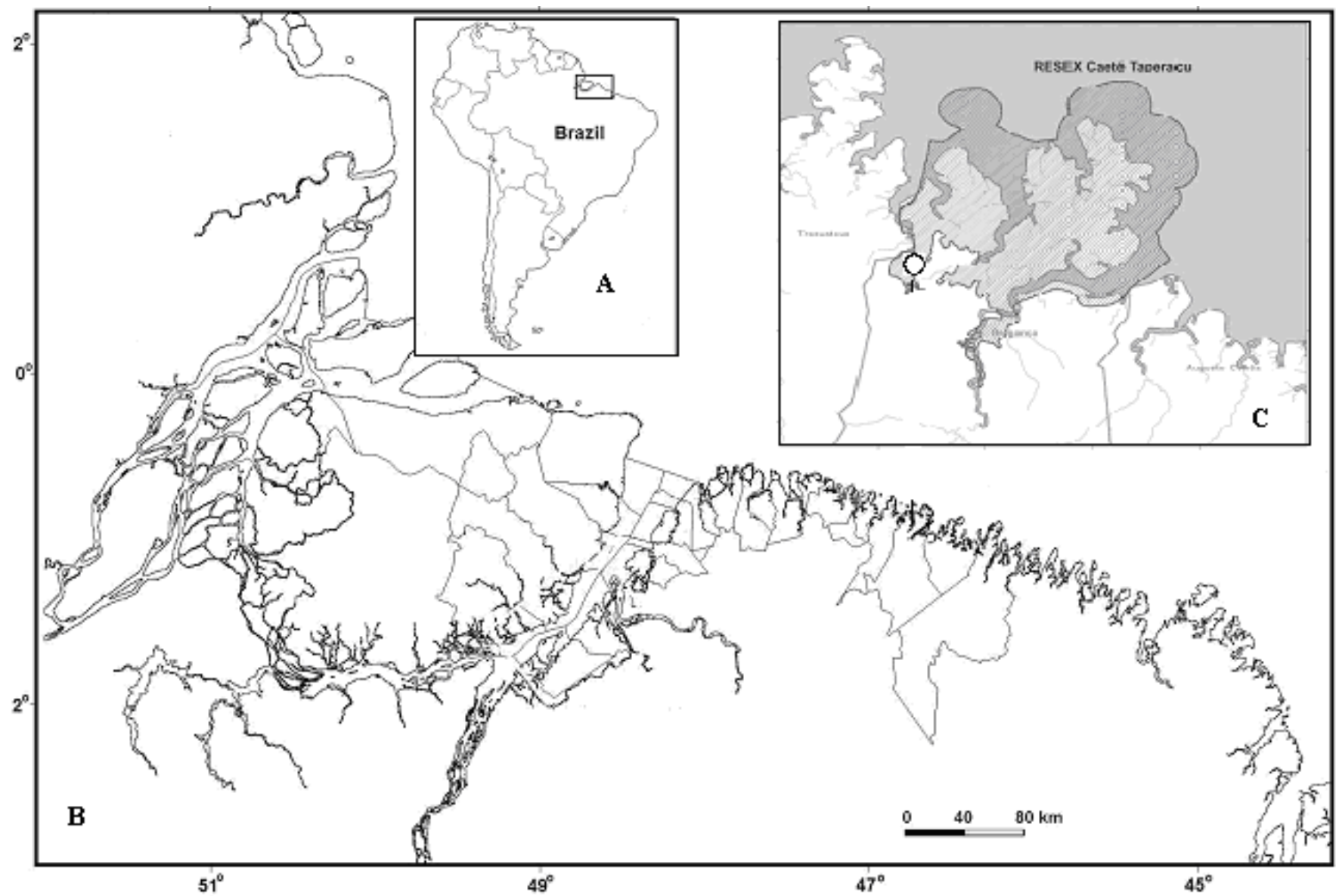

Figura 1. Localização da área de estudo. (A) Brasil, (B) zona costeira amazônica brasileira, (C) localização da comunidade do Tamatateua.

O clima da região é quente e úmido, com uma estação chuvosa durante os meses de dezembro a maio e uma estação seca, ou de menos chuva, nos demais meses do ano. A pluviosidade média anual varia de 2.500 a $3.000 \mathrm{~mm}$. A temperatura situa-se entre $20,4^{\circ} \mathrm{C}$ e $32,8^{\circ} \mathrm{C}$, com média de $26,6^{\circ} \mathrm{C}$. A umidade relativa do ar oscila entre 80 e 91\% (INMET, 1992; MARTORANO et al., 1993).

A Planície Costeira Bragantina é caracterizada pela ocorrência de manguezais que ocupam 95\% de toda a área costeira da mesma, sendo os bosques de mangue compostos basicamente pelas espécies de Rhizophora mangle, Laguncularia racemosa e Avicennia germinans, sendo a $R$. mangle a espécie dominante (MARQUES et al., 1997; PROISY et al., 2003).

Os campos naturais de Tamatateua são cobertos, principalmente, por juncos (Aleucharis sp) e por macrófilas aquáticas, que durante o período chuvoso transformam-se em campos alagados que servem como fonte de água e de pastagem para o gado (bovino e bubalino), bem como de hábitat para várias espécies de peixes, que são utilizados como complemento alimentar (pesca de subsistência) por algumas famílias locais (OLIVEIRA, 2005).

\subsection{PROCEDIMENTOS METODOLÓGICOS}

Para avaliar de forma integrada os diferentes aspectos socioeconômicos e ambientais da comunidade em 
estudo, diferentes ferramentas metodológicas foram utilizadas, sendo: aplicação de questionários, entrevistas, observações diretas e mensuração de alguns fatores de degradação ambiental.

Primeiramente foram aplicados questionários semi-sistemáticos, compostos por três blocos de perguntas (perfil socioeconômicos, condição de vida e moradia e opinião e percepção dos moradores sobre os problemas ambientais). Este trabalho foi realizado em 100\% das residências.

Para a caracterização do perfil socioeconômico de todos os moradores foram levantadas informações sobre idade, sexo, estado civil, escolaridade, ocupação/profissão e renda.

A condição de vida e moradia dos habitantes de cada residência foi determinada através do levantamento dos aspectos físicos do domicílio (tipo de telhado, construção e piso, e presença de banheiro), dos serviços públicos disponíveis (destino dos resíduos sanitários, energia elétrica, abastecimento de água, transporte e coleta de lixo) e da situação da propriedade (própria, alugada, de familiares e/ou invadida). Para determinar a condição de vida e moradia mínima aceitável foi utilizado o Índice de Condições de Vida e Moradia (ICV-MO) que foi calculado de acordo com metodologia, descrita por Costa (2004), seguindo o padrão utilizado pelo Índice de Desenvolvimento Socioeconômico desenvolvido pela Fundação de Economia e Estatística (IDESE/FEE), através da fórmula (ICV-MO = (p1 x IAF) + (p2 x ISP) + (p3 x IP)), sendo IAF os Aspectos Físicos da Moradia, ISP os Serviços Públicos à disposição da comunidade e o IP a Situação da Propriedade.

Com relação à opinião e percepção dos moradores sobre os problemas ambientais, os questionários foram elaborados de acordo com os trabalhos de Morgan et al. (1995) e LEATHERMAN (1997) e aplicados a um membro de cada residência.

Os tipos de infraestrutura e serviços disponíveis para a comunidade (ex. saúde, saneamento básico, educação, transporte, etc.) foram levantados simultaneamente à aplicação dos questionários semisistemáticos, a partir de observação direta, seguindo a metodologia de check list, aplicada por JUNYENT (1999) e PEREIRA et al. (2003), adaptada à realidade local, bem como através de entrevistas.

Com base na opinião e percepção dos moradores, bem como na observação direta realizada, em relação à infraestrutura e serviços disponíveis e a condição ambiental da comunidade, metodologias específicas foram adotadas para mensurar/analisar alguns problemas ambientais apontados/detectados, tais como: o acúmulo de lixo doméstico, a qualidade da água para consumo, o desmatamento e o uso do solo para agricultura.

Abaixo segue a metodologia aplicada:

(i) Produção de lixo doméstico: primeiramente foi analisado o destino dado ao lixo (coletado pela prefeitura, queimado, enterrado, jogado em terrenos baldios, campos, etc.) Em seguida, o trabalho de mensuração do lixo foi realizado por meio de duas amostragens, uma no final do mês de setembro e a outra no início do mês de novembro de 2006, sendo cada amostragem representada pelo lixo produzido durante dois dias em $30 \%$ do total de casas da comunidade. Com base na média das duas amostragens foi estimada a produção de lixo mensal para $100 \%$ das residências da comunidade. Em cada amostra coletada o lixo orgânico (não reciclável) foi pesado separadamente do lixo inorgânico (reciclável), em seguida foram realizadas análises de variação de produção (início e final do mês). Para determinar a normalidade 
e a homogeneidade dos dados foram realizados os testes de Lilliefors (CONOVER, 1971) e Bartlett's (SOKAL; ROHLF, 1969), respectivamente, com auxílio do programa STATISTICA 6.0 (STATSOFT, 2001). Quando os dados não apresentaram distribuição normal, utilizou-se transformações $\log (\mathrm{x}+1)$. Para os dados normais foi aplicada a análise de variância (ANOVA - one way), seguida pelo teste post-hoc de Fisher LSD. Porém quando as variâncias foram heterogêneas, foi aplicado o teste não-paramétrico de Mann-Whitney (Teste U). Os trabalhos foram realizados baseando-se no manual "Compromisso Empresarial para Reciclagem" (1995), e no manual "Gestão integrada de resíduos sólidos na Amazônia" (IBAM, 2005), sendo ambas as metodologias adaptadas à realidade local.

(ii) Qualidade da água: a coleta das amostras foi realizada durante o período seco (novembro) e o período chuvoso (março) em dois poços comunitários. O Poço 1 está situado no Porto do Atalaia (46 ${ }^{\circ}$ 44' 42.123' ' W - 1' 3' 6.73' ' S) e o Poço 2 na Escola das Quatro Bocas (46 47' 16.237' W - $0^{\circ}$ 56' 9.037' S). Estes poços foram escolhidos por terem grande importância, atendendo um grande número de moradores da comunidade. Todas as análises físico-químicas foram realizadas no Laboratório de Oceanografia Costeira e Estuarina da UFPA, seguindo metodologias e/ou utilizando equipamentos específicos para cada variável estudada. A cor real e aparente foi analisada pelo equipamento Color of water HI 93727 Hannna Instrument, a turbidez pelo Microprocessor Turbidity Meter HI 93703 Hanna Instrument, o $\mathrm{pH}$ pelo Labmeter model $\mathrm{pH} 2$ - pHs-3B, a salinidade pelo Multianalizador Corning Checkmate II, a temperatura pelo Termômetro Incoterm L-168/04, o ferro dissolvido pelo Hardness \& Iron HI 93741 Hanna Instrument, e os coliformes fecais e totais a partir da técnica denominada de tubos múltiplos, seguindo os procedimentos da American Public Health Association (2004). Para a classificação da qualidade da água, os procedimentos foram realizados utilizando os parâmetros estabelecidos por resoluções específicas, de acordo com ANVISA (2004) e CONAMA (1986; 2000; 2005).

(iii) Desmatamento (corte de árvores): o desmatamento foi mensurado com base nas respostas obtidas por entrevistas e pela aplicação de questionários aos moradores da comunidade, no qual foram abordadas perguntas referentes ao extrativismo vegetal (corte de capoeira ou mangue), bem como por meio de observações diretas, baseadas no método de Greenwood (1973).

(iv) Uso do solo para agricultura: por meio de aplicação de questionários e de observações diretas foram identificadas as áreas de cultivo, as práticas/tipos de agricultura e as técnicas de manejo do solo mais empregadas na comunidade em estudo, como a forma de aragem da terra, uso ou não de agrotóxicos e fertilizantes; derrubadas da capoeira e uso de queimadas. Seguindo o método de Greenwood (1973).

\section{RESULTADOS E DISCUSSÕES}

\subsection{PERFIL SOCIOECONÔMICO}

A população de Tamatateua é de 966 pessoas, totalizando 207 famílias, com um valor médio de 4,66 pessoas por casa. A maioria dos moradores é jovem ( $<20$ anos - 52\%), do sexo masculino (55\%), solteiro (62\%), e com ensino fundamental incompleto (60\%). Entre as atividades de ocupação/profissão exercidas pela população total, a agricultura familiar representa $48 \%$, seguida por estudante $35 \%$, pesca $9 \%$, aposentado $3 \%$, funcionário público $2 \%$ e outros $3 \%$. Cabe ressaltar que a atividade da pesca aparece com índice de apenas $9 \%$, em decorrência da autodenominação de profissão (agricultor) dada pelos trabalhadores dessa comunidade, todavia a pesca é realizada como uma atividade paralela e complementar por praticamente todos aqueles que praticam a agricultura, denominando assim, essa 
comunidade de agro-pesqueira. Por outro lado, $64 \%$ das famílias sobrevivem com menos de um salário mínimo por mês.

A baixa renda per capita, possivelmente, é consequência do baixo grau de escolaridade que os moradores de Tamatateua possuem, bem como da falta de opções de atividades econômicas (GRASSO, 2000). Estes resultados são similares aos que Krause; Glaser (2003), Silva et al. (2006), Pereira et al. (2006a) e Pereira et al. (2006b) encontraram em estudos semelhantes realizados em outras comunidades da região bragantina, fato que comprova a difícil realidade social e econômica das populações inseridas no litoral amazônico.

Por outro lado, essa comunidade apresenta uma boa estrutura em termos de associações comunitárias e.g associação de moradores, associação de produtores de mel, associação de mulheres, entre outras. Entre as principais conquistas das associações podem ser citados os financiamentos rurais, que vêm auxiliando a agricultura familiar, além de outras atividades que vêm contribuindo para o desenvolvimento sustentável local, como por exemplo, a extração/produção de mel. Estes fatos estão relacionados diretamente ao estabelecimento do capital social (BERKES; FOLKE, 1998) e à liderança local, sendo estes, prérequisitos extremamente necessários nas colaborações e/ou cooperações de órgãos nacionais e/ou internacionais (KLOSE et al., 2005), que visam o desenvolvimento de ações comunitárias para a melhoria na qualidade de vida das populações rurais.

\subsection{CONDIÇÕES DE VIDA E MORADIA/INFRA-ESTRUTURA E SERVIÇOS}

Com relação ao Índice de Condição de Vida e Moradia ICV-MO, da comunidade de Tamatateua, a média encontrada foi de 0,548 , valor inferior à condição mínima aceitável que é de 0,707, segundo o Índice de Desenvolvimento Socioeconômicos criado pela Fundação de Economia e Estatística (IDESE/FEE). Este fato é decorrente da precariedade dos aspectos físicos e sanitários da moradia, e da infraestrutura e serviços públicos disponíveis à população. A maioria das casas é de barro, com chão de terra batido, sendo algumas cobertas por palhas (folhas de palmeira seca), não possuindo banheiro nem sistema de água canalizada e/ou tratada, a água utilizada para consumo da população é oriunda de poços comuns que são escavados nos terrenos das residências, muitas vezes próximos às fossas negras que não recebem nenhum tipo de tratamento. De acordo com Sánchez-Gil et al. (2004), a ausência de desenvolvimento social e econômico, decorrente principalmente das poucas opções de atividades econômicas em comunidades pesqueiras, é sem dúvida a principal causa dos problemas de estrutura física destas residências.

A comunidade não possui nenhum sistema de tratamento de esgoto, bem como de coleta de lixo. Tamatateua também não dispõe de postos de saúde, sendo que nas situações mais graves, o atendimento é realizado no posto de saúde da comunidade de Bacuriteua ou nos hospitais e/ou postos município de Bragança. As doenças mais freqüentes são: malária, gripe, diarréia, viroses e doenças de pele. Segundo os moradores, a malária é a doença que mais vem atingindo a comunidade nos últimos anos, e de acordo com Rodrigues; Moreira (2006), este fato está associado, principalmente, à falta de saneamento básico e ao aumento do desmatamento na região.

Quanto ao ensino, a comunidade é atendida por apenas três escolas públicas, que oferecem o ensino fundamental incompleto. Aos interessados em continuar os estudos, a única opção são as escolas do município de Bragança., que apesar do transporte público municipal ser oferecido gratuitamente, os 
demais custos da educação, aliados às poucas opções de horários dos ônibus escolares, são fatores que impedem ou dificultam a continuidade dos estudos entre a maioria dos habitantes locais, fato que justifica a baixa escolaridade da população local. Resultados similares foram encontrados em outros estudos realizados em comunidades rurais do litoral amazônico (KRAUSE et al., 2000; GLASER, 2003; KRAUSE; GLASER, 2003).

Estudos de ICV-MO realizados por Costa (2004), em comunidades costeiras do sul do Brasil, demonstram que os baixos valores dos índices encontrados nessas comunidades, tanto do norte quanto do sul do país, não são considerados ideais, e que estes baixos índices são decorrentes, principalmente, dos problemas de acesso aos serviços públicos e infraestrutura, bem como aos poucos ou ineficazes investimentos sociais e/ou da falta de incentivos governamentais aplicados nessas áreas.

\subsection{OPINIÃO E PERCEPÇÃO SOCIOAMBIENTAL}

De acordo com a opinião e percepção socioambiental dos moradores (tabela 1), os principais problemas estão relacionados à precariedade dos serviços públicos, principalmente, à falta de saneamento básico (coleta de lixo, abastecimento de água tratada e rede de canalização e tratamento de esgoto), bem como, à degradação e/ou uso inadequado dos recursos naturais (redução dos recursos pesqueiros e florestais, pesca predatória, desmatamento do manguezal e redução da fertilidade do solo).

Tabela 1. Principais problemas ambientais apontados pela população de Tamatateua - PA.

\begin{tabular}{|c|c|c|}
\hline Problemas Socioambientais & Frequência de Respostas* & $\%$ \\
\hline \multicolumn{3}{|c|}{1 - Decorrentes da falta de saneamento básico } \\
\hline $\begin{array}{l}\text { Presença de lixo na área } \\
\text { residencial da comunidade }\end{array}$ & 128 & 62 \\
\hline $\begin{array}{c}\text { Presença de lixo na área de } \\
\text { manguezal e rios }\end{array}$ & 74 & 36 \\
\hline $\begin{array}{c}\text { Doenças decorrentes de água } \\
\text { contaminada e falta de sistema de } \\
\text { esgoto }\end{array}$ & 62 & 30 \\
\hline $\begin{array}{l}\text { Degradação do solo por acúmulo } \\
\text { de lixo e esgotos }\end{array}$ & 37 & 18 \\
\hline \multicolumn{3}{|c|}{2 - Decorrentes da degradação dos recursos naturais } \\
\hline $\begin{array}{c}\text { Redução dos recursos pesqueiros } \\
\text { e florestais }\end{array}$ & 125 & 60 \\
\hline $\begin{array}{l}\text { Pesca predatória/indiscriminada } \\
\text { (peixes, caranguejo, etc.) }\end{array}$ & 56 & 27 \\
\hline Desmatamento do manguezal & 50 & 24 \\
\hline
\end{tabular}




\begin{tabular}{|c|c|c|}
\hline $\begin{array}{c}\text { Redução da } \\
\text { produtividade/fertilidade do solo }\end{array}$ & 48 & 23 \\
\hline \multicolumn{3}{|c|}{ 3-Outros } \\
\hline $\begin{array}{c}\text { Não sabem responder as } \\
\text { perguntas }\end{array}$ & 09 & 04 \\
\hline $\begin{array}{l}\text { Não existem problemas } \\
\text { ambientais na área da } \\
\text { comunidade }\end{array}$ & 27 & 13 \\
\hline
\end{tabular}

* Frequência de resposta para $\mathrm{N}=207$ (número de residências).

A tabela 1 mostra que apenas $4 \%$ dos entrevistados não souberam responder às perguntas, porém $13 \%$ responderam que não existem problemas ambientais na área da comunidade.

De acordo com as demais respostas, foi possível perceber que a população tem uma boa opinião e percepção à respeito dos principais problemas socioambientais que vêm ocorrendo na área. No entanto, os mesmos, apesar de apresentar uma boa estruturação comunitária, são bastante negativos quanto a expectativas futuras em relação à conservação do meio ambiente, mesmo conscientes do fato de que estão em uma unidade de conservação e que os recursos naturais são a principal fonte de sobrevivência local (OLIVEIRA, 2004).

\subsection{PRODUÇÃO DE LIXO DOMÉSTICO}

A área de estudo não dispõe de sistema público de coleta do lixo, e em decorrência, 30\% das casas estudadas lançam seus lixos em terrenos baldios, campos, estuários, rios, etc.; enquanto $70 \%$ queimam ou enterram o lixo. Entretanto, durante o período chuvoso, a queima não é realizada nos dias de maiores precipitações pluviométricas e o lixo produzido passa a ser jogado no entorno da comunidade e.g. ruas, escolas, rios, manguezal, quintal das casas, etc.

Considerando $100 \%$ das residências da comunidade, a produção média mensal de lixo é de, aproximadamente, $2.680,750 \mathrm{~kg}$, apresentando uma produção per capita mensal de 2,775 kg, ou seja, uma média de $\pm 0,093 \mathrm{~kg} /$ dia, estando muito abaixo da produção média nacional, que segundo o IBAM (2005), nas cidades com menos de 200.000 moradores a produção é de 0,450 a 0,700 kg/dia de lixo por habitante. Essa média diária tão baixa pode estar diretamente relacionada à questão da baixa renda da maioria de seus habitantes, o que gera maiores dificuldades de acesso aos bens de consumo, bem como a questão da sua posição geográfica, pois Tamatateua está localizada na zona rural, não estando inserida no “elevado ciclo" de produção de resíduos que ocorre no ambiente urbano.

Com a realização da repetição da amostragem, foi possível comprovar que há um aumento na produção de lixo doméstico no início do mês (coleta 2), tendendo a diminuir no final do mesmo (coleta 1), isso se deve ao fato de que no início do mês as famílias recebem salários, aposentadorias, benefícios do governo, etc. Embora tenham ocorrido variações na produção do lixo no decorrer do mês, estatisticamente essas diferenças não foram significativas $(\mathrm{U}=1695 ; \mathrm{p}=0,8086)$. 
Entre os componentes do lixo inorgânico, o plástico predominou com $41 \%$ do valor total, seguido por papel/papelão com 20\%, dentre outros (Figura 2A). Comparando a produção do lixo orgânico com a do inorgânico não foi possível registrar diferenças significativas $(\mathrm{F}=3,62 ; \mathrm{p}=0,0595 ; \mathrm{F}=2,67 ; \mathrm{p}=0,1045$, respectivamente) entre as amostragens 1 e 2, embora as percentagens de lixo inorgânico tenham sido levemente superiores visualmente (Figura 2B), fato que difere do "padrão" nacional, no qual, cerca de, $65 \%$ do lixo domiciliar produzido é constituído por lixo orgânico.

A)

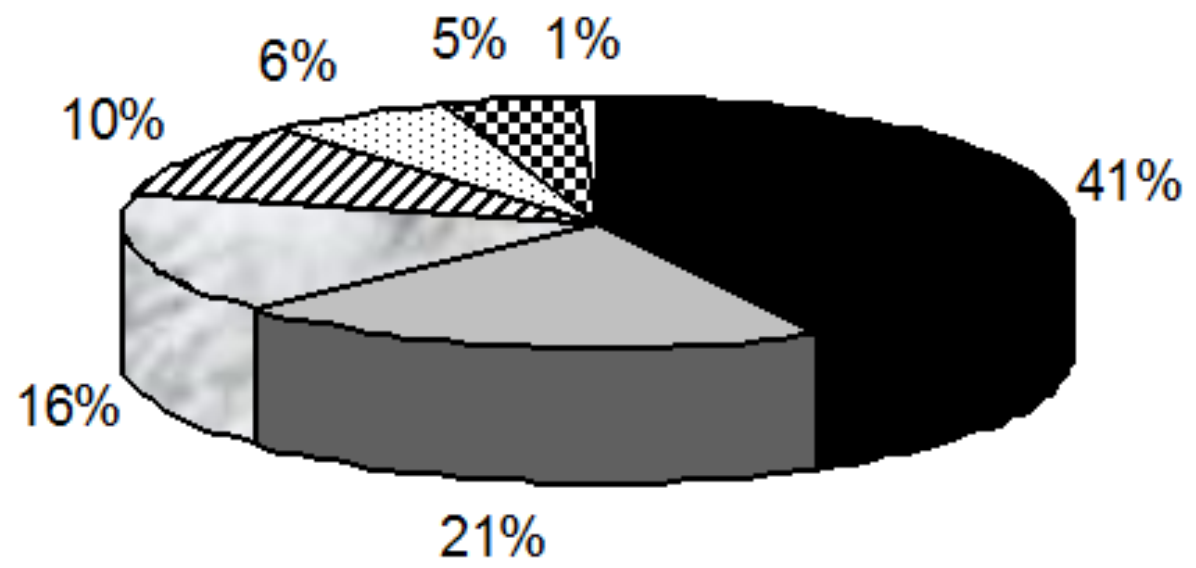

\begin{tabular}{|c|c|}
\hline $\begin{array}{l}\text { Plástico } \\
\text { a Vidro } \\
\text { a lsopor }\end{array}$ & $\begin{array}{l}\square \text { Papel/papelão } \\
\square \text { Pano }\end{array}$ \\
\hline
\end{tabular}

B) 


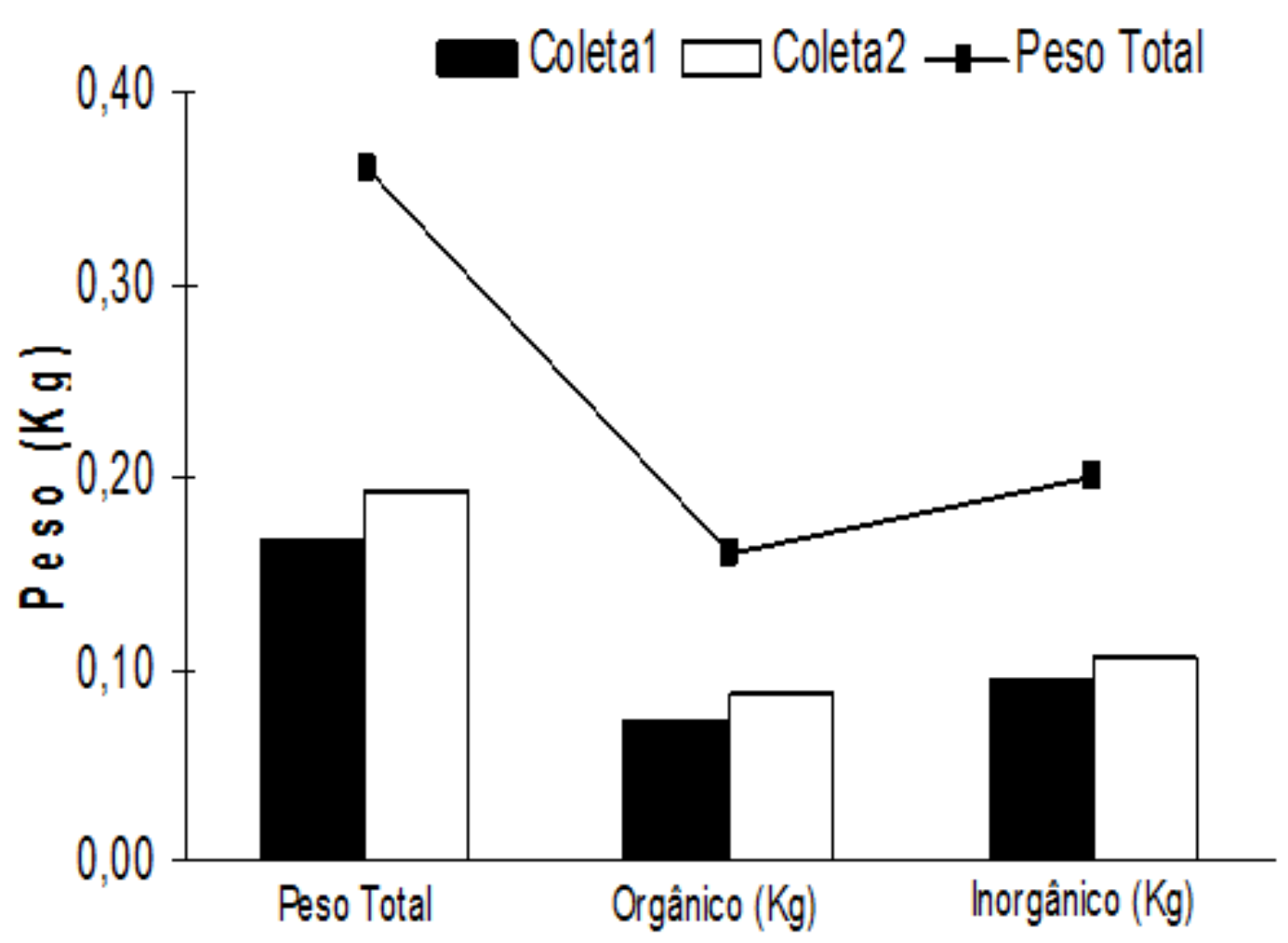

Figura 2. Composição (\%) do lixo inorgânico (A) e Produção (kg) do lixo orgânico e inorgânico, em ambas as amostragens (B).

Em Tamatateua, bem como em outras comunidades do litoral amazônico, o lixo orgânico comestível serve de alimento para muitos animais de pequeno porte, como pato, galinha, cachorro, etc. Apesar de ocorrer de forma involuntária, a comunidade em estudo vem seguindo as recomendações de Pereira Neto (1996), no que concerne a tratar e/ou transformar os resíduos orgânicos (neste caso em alimento para os animais), reduzindo assim, os vários problemas ambientais e sanitários associados ao acúmulo dos mesmos.

No entanto, o volume de lixo sólido produzido nesta área, associado à falta de coleta do mesmo constituem uma séria ameaça a todos os ecossistemas ali presentes (rios, manguezal, estuários, etc.), bem como à saúde humana. Entre os principais problemas sociambientais, decorrentes do acúmulo de lixo local podem ser destacados: a presença de vetores (mosquitos, moscas, ratos, baratas, etc.) que podem provocar doenças como dengue, malária, micoses, verminoses, etc.; a contaminação do solo e dos recursos hídricos locais; a produção de gases que provocam mau cheiro; além dos impactos estéticos e econômicos (GRIMBERG; BLAUTH, 1998). Resultados similares foram encontrados em outras comunidades da região norte e nordeste do país (SOUZA-FILHO, 2001; ARAÚJO; COSTA, 2003; PEREIRA et al., 2003; SILVA et al., 2006).

\subsection{QUALIDADE DA ÁGUA PARA CONSUMO}

A falta de abastecimento público de água potável é um dos principais problemas apresentados na comunidade do Tamatateua. Por esta razão, vários poços comunitários e particulares foram construídos ao 
longo da comunidade, entretanto durante um período seco prolongado, muitos destes poços secam. Por outro lado, a pouca profundidade e/ou a proximidade dos mesmos, em relação às fossas sanitárias, que ocorre em alguns casos, podem contribuir para que a qualidade da água subterrânea seja comprometida (AZEVEDO, 2006).

Os resultados das análises físico-químicas realizadas em dois poços mostram algumas variações na concentração dos seus constituintes em solução, o que pode ser prejudicial à saúde das pessoas (Tabela 2).

A cor real e a cor aparente apresentaram valores muito elevados durante o período seco em ambos os poços analisados, estando muito acima dos parâmetros estabelecidos pelas resoluções vigentes (Tabela 2). Geralmente, a variação de cor da água está relacionada à turbidez e/ou à concentração de ferro dissolvido (NASCIMENTO; BARBOSA, 2005). Na área em estudo, estas variáveis parecem não influenciar diretamente a cor aparente e real da água, pois apenas no poço 2, durante o período chuvoso, o ferro aparece com valor elevado, período em que a água não apresentou variação de cor. Entretanto, segundo a ANVISA (2004) água potável não deve apresentar coloração alguma.

\section{Parâmetros}

